\title{
Diversidade genética e paternidade de progênies de Brycon orbignyanus obtidas por diferentes sistemas reprodutivos
}

\section{Genetic diversity and paternity of Brycon orbignyanus offspring obtained for different reproductive systems}

\author{
Nelson Mauricio Lopera-Barrero ${ }^{1 *}$; Camilo Andres Reyes Alvarez ${ }^{2}$; \\ Maria del Pilar Rodriguez-Rodriguez ${ }^{3}$; Jayme Aparecido Povh4; Lauro Vargas; \\ Danilo Pedro Streit Júnior ${ }^{6}$; Rodolfo Nardez Sirol7 ; Ricardo Pereira Ribeiro ${ }^{5}$
}

\section{Resumo}

O objetivo do presente estudo foi avaliar a diversidade genética e a paternidade de progênies de Brycon orbignyanus obtidas pelos sistemas reprodutivos por extrusão e seminatural, através do marcador microssatélite. Os quatro loci utilizados produziram 11 alelos, sendo observados três alelos (BoM1, BoM5 e BoM7) e dois alelos (BoM2) por locus presentes nos parentais e na progênie de ambos sistemas reprodutivos. Na progênie do sistema por extrusão foram observados alelos de baixa frequência para os locus BoM5 (alelo $\mathrm{B}=0,095$ ) e BoM7 (alelo $\mathrm{C}=0,059$ ) e houve uma diminuição da variabilidade genética (Heterozigosidade observada- $H \mathrm{o}=0,900$ e 0,823; Índice de Shannon-IS $=0,937$ e 0,886; diversidade genética de Nei-DGN $=0,604$ e 0,566 , respectivamente). Na progênie do sistema seminatural as frequências dos alelos se mantiveram estáveis, sendo verificada uma frequência desigual para cada locus. A variabilidade genética foi preservada, sendo corroborado pelos valores de $H \mathrm{o}(0,975$ e 0,945$)$, IS $(0,927$ e 0,924$)$ e DGN $(0,593$ e 0,581$)$ para parentais e progênie, respectivamente. Observaramse desvios $(\mathrm{P}<0.01)$ no equilíbrio de Hardy-Weinberg e desequilíbrio de ligação nos dois sistemas reprodutivos. O coeficiente de endogamia (Fis) mostrou déficit de heterozigotos na progênie do sistema por extrusão. Observou-se paternidade múltipla e contribuição reprodutiva diferenciada na composição das famílias na progênie nos dois sistemas reprodutivos, com a presença de dominância reprodutiva no sistema seminatural.

Palavras-chave: Conservação genética, microssatélite, piracanjuba, programa de repovoamento, sistema por extrusão, sistema seminatural

\begin{abstract}
The objective of this study was to estimate the genetic diversity and the paternity of Brycon orbignyanus offspring's obtained with the extrusion and semi-natural reproductive systems, by microsatellites
\end{abstract}

1 Prof. Dr. em Zootecnia, Dept ${ }^{\circ}$ de Zootecnia, Universidade Estadual de Londrina, UEL, Londrina, PR. E-mail: nmlopera@uel.br

2 Biólogo, Mestrando em Tecnologia e Higiene de Alimentos, Universidad Nacional de La Plata, Av. 7, nº 877, La Plata, Buenos Aires, Argentina. E-mail: chaca53@hotmail.com

3 M.e em Zootecnia, Dept ${ }^{\circ}$ de Zootecnia, Universidade Estadual de Maringá, UEM, Maringá, PR. E-mail: pilar.peixegen@gmail. com.

4 Prof. Dr. em Zootecnia, Universidade Federal do Mato Grosso do Sul, Faculdade de Medicina Veterinária e Zootecnia, Campo Grande, MS. E-mail: jayme.peixegen@gmail.com

5 Profs. Drs. em Zootecnia, Dept ${ }^{\circ}$ de Zootecnia UEM, Maringá, PR. E-mail: 1vargas@uem.br; rpribeiro@uem.br

6 Prof. Dr. em Zootecnia, Dept ${ }^{\circ}$ de Zootecnia Universidade Federal do Rio Grande do Sul, UFRGS, Porto Alegre, RS. E-mail: danilo.streit@ufrgs.br

7 Pesquisador Dr. em Zootecnia, Companhia Paulista de Força e Luz, CPFL, Campinas, SP. E-mail: rnsirol@cpfl.com.br Autor para correspondência 
markers. The four loci used produced 11 alleles, being observed three alleles (BoM1, BoM5 and BoM7) and two alleles (BoM2) for locus present in the parental and in the offspring of both reproductive systems. In the offspring of the extrusion system low frequency alleles was observed for the locus BoM5 (allele $\mathrm{B}=0.095$ ) and $\mathrm{BoM} 7$ (allele $\mathrm{C}=0.059$ ) and there was a decrease of genetic variability (observe heterozygosity-Ho $=0.900$ and 0.823 ; Shannon index-IS $=0.937$ and 0.886 ; Nei genetic diversity-DGN $=0.604$ and 0.566 , respectively). For the offspring of the semi-natural system the allele frequencies stayed stable being verified an unequal frequency for each locus. The genetic variability in the offspring was preserved, being corroborated by the Ho values (0.975 and 0.945), IS (0.927 and 0.924) and DGN (0.593 and 0.581$)$ for parental and offspring, respectively. Deviations were observed $(\mathrm{P}<0.01)$ in the Hardy-Weinberg equilibrium and linkage disequilibrium for the two reproductive systems. The inbreeding coefficient (Fis) it showed deficit of heterozygote in the offspring of the extrusion system. Multiple paternity and differed reproductive contributions in the composition of the families in the offspring in the two reproductive systems was observed, with the presence of reproductive dominance in the semi-natural system.

Key words: Extrusion system, genetic conservation, microsatellite, piracanjuba, restocking program, semi-natural system

\section{Introdução}

A piracanjuba, Brycon orbignyanus (Characiformes, Characidae, Bryconinae) também conhecida como bracanjuva, é uma espécie nativa das bacias formadas pelos rios Uruguai e Paraná (ZANIBONI-FILHO; REYNALTE-TATAJE; WEINGARTNER, 2006). Devido ao seu elevado valor comercial, qualidade da carne, precocidade, adaptação ao cativeiro e voracidade e briga na pesca esportiva é uma espécie de grande interesse por produtores e pescadores (BORBA; FRACALOSSI; PEZZATO, 2006, CECCARELLI; SENHORINI; RÊGO, 2005). Entretanto, a diminuição de suas populações naturais em varias bacias hidrográficas - catalogada como espécie em risco de extinção (IBAMA, 2012) e a perda de diversidade genética em estoques e populações naturais (PANARARIANTUNES et al., 2011) têm chamado a atenção de pesquisadores. A perda de variabilidade genética pode levar a depressão por endogamia que causa diminuição no desempenho e sobrevivência de progênies, incluindo aquelas liberadas em programas de conservação (PEREZ-ENRIQUEZ et al., 2009; POVH et al., 2008).

Das ações empregadas para mitigar a diminuição de populações naturais de peixes destacamse os programas de repovoamento (LOPERABARRERO; RIBEIRO; POVH, 2007). De acordo com Kalinowski et al. (2012), as principais metas que um programa de repovoamento deve alcançar quando se trata de peixes em risco de extinção (como é o caso do B. orbignyanus) são: 1) evitar a perda completa do grupo de genes; 2) conservar o máximo possível a diversidade genética; 3 ) realizar as metas 1 e 2 sem comprometer a sobrevivência das populações através do tempo.

Desta forma, introduções de peixes realizadas de forma irracional ou sem apoio científico podem provocar redução da variabilidade genética nas populações naturais, devido principalmente a manejos reprodutivos realizados de forma errada nos estoques, os quais podem reduzir o potencial evolutivo e a resposta a modificações ambientais das progênies (POVH et al., 2011; RICHARDS; WARES; MACKIE, 2010). Neste último aspecto, a utilização de um número insuficiente de reprodutores (MELO et al., 2006) ou de sistemas reprodutivos inadequados $(\mathrm{POVH}, 2007)$ podem promover a diminuição da variabilidade genética das progênies que serão liberadas durante o repovoamento. De acordo com Gardner et al. (2010), a compreensão de como o programa de repovoamento atua biológica e geneticamente nas populações selvagens, o monitoramento e a avaliação do progresso dos peixes liberados é uma responsabilidade e uma necessidade. 
De forma geral, existem dois sistemas reprodutivos que são utilizados para espécies migratórias brasileiras: o sistema por extrusão e o sistema seminatural (ZANIBONI-FILHO; NUÑER, 2004). O sistema reprodutivo por extrusão é um dos mais utilizados na reprodução de espécies migratórias. Este sistema não requer tanques de desova e permite manipular facilmente os gametas. Porém, a manipulação física do animal infringe um alto estresse (que em algumas espécies pode causar altas taxas de mortalidade) e a sua utilização pode diminuir a variabilidade genética. O sistema reprodutivo seminatural, pelo contrario, apresenta menor interferência do produtor no processo reprodutivo, reduz o estresse e diminui a mortalidade de reprodutores (LOPERABARRERO, 2009). Entretanto, nesse sistema têm se verificado comportamentos de dominância reprodutiva que podem influenciar a variabilidade genética nas progênies (POVH, 2007). Dessa forma, são necessárias pesquisas que permitam confirmar a eficiência desses sistemas na preservação dos reprodutores utilizados nos acasalamentos e na variabilidade genética das progênies utilizadas em programas de repovoamento e associa-las com a conservação genética de populações naturais de peixes.

O objetivo do estudo foi avaliar a diversidade genética e a paternidade de progênies de Brycon orbignyanus obtidas pelos sistemas reprodutivos por extrusão e seminatural, através de marcadores microssatélites.

\section{Material e Métodos}

O experimento foi realizado nas instalações do laboratório de Biologia Molecular do Núcleo de Pesquisa Peixegen, na Universidade Estadual de Maringá (UEM). Utilizaram-se 20 reprodutores (10ð̄ e 10ㅇ) de B. orbignyanus selecionados de um estoque mantido em cativeiro na Estação de Aquicultura da Duke Energy International, localizada na cidade de Salto Grande $\left(49^{\circ} 13^{\prime} \mathrm{W}\right.$ e $23^{\circ} 10^{\prime} S$ ), São Paulo, Brasil. O estoque foi formado a partir de reprodutores capturados no rio Paraná, onde permaneceu inalterado (sem introdução de novos indivíduos) durante seis anos desde o momento da sua formação. Esses indivíduos foram utilizados em programas de repovoamento realizados no rio Paranapanema, SP.

Os sistemas reprodutivos analisados (sistema por extrusão e seminatural), foram caracterizados por Zaniboni-Filho e Nuñer (2004). Nos dois sistemas os peixes foram induzidos à reprodução com extrato de hipófise de carpa. As fêmeas receberam 5,5 mg/ $\mathrm{kg}$, divididos em duas aplicações: 10\% do total na primeira aplicação e $90 \%$ restante 12 horas depois. Os machos receberam $2,5 \mathrm{mg} / \mathrm{kg}$ em dose única paralelamente com a última dose das fêmeas.

Sistema por extrusão: aproximadamente seis horas depois da última indução (160 horas-grau, $27^{\circ} \mathrm{C}$ ) os óvulos de cinco fêmeas e o sêmen de cinco machos (1:1) foram obtidos através de pressão manual crânio-ventral realizada no abdômen. Os gametas foram depositados num recipiente plástico seco até a verificação da desova completa dos indivíduos (ausência de liberação de gametas), e em seguida, adicionou-se $15 \%$ de água sobre o peso total dos óvulos, iniciando-se o processo de fertilização. Os ovos foram dispostos em incubadoras cilíndricocônicas com fluxo constante de intercambio de água, finalizando o processo com a eclosão. Simultaneamente com a coleta dos gametas foram tomadas amostras de nadadeira caudal $\left(0,5 \mathrm{~cm}^{2}\right)$ de cada reprodutor (10 amostras no total). Três dias depois da eclosão dos ovos, coletaram-se de forma aleatória 200 larvas completas de todas as incubadoras, sendo escolhidas 60 larvas para realizar a análise da progênie. Todas as amostras (nadadeiras e larvas) foram acondicionadas em microtubos de 1,5 $\mathrm{ml}$ contendo álcool etílico absoluto para a posterior extração do DNA. A porcentagem de mortalidade dos reprodutores utilizados no acasalamento definiu-se um dia depois da reprodução. 
Sistema seminatural: dez reprodutores (cinco machos e cinco fêmeas) foram acondicionados num tanque circular com um raio de 5,1 m x 1,85 m de profundidade média, abastecido por fluxo continuo de água $(131 \mathrm{~L} / \mathrm{s})$. Aproximadamente seis horas depois da última indução (160 horas-grau, $27^{\circ} \mathrm{C}$ ) iniciou-se o período de coleta de ovos. Um tubo localizado na parte central do tanque permitiu o direcionamento dos ovos para uma estação coletora, onde foram vertidos numa incubadora cilíndrocônica de captação de 200 litros com fluxo continuo de água (7 L/s). Estabeleceu-se um período de coleta de no máximo seis horas, com a retirada de ovos a cada hora da incubadora de captação, sendo em seguida conduzidos a incubadoras cilíndro-cônicas onde ocorreu a incubação. Depois das seis horas de coleta de ovos foi verificado por pressão abdominal se os machos e fêmeas utilizados desovaram completamente e paralelamente foram tomadas amostras de nadadeira caudal $\left(0,5 \mathrm{~cm}^{2}\right)$ de cada reprodutor (10 amostras no total). Três dias depois da eclosão dos ovos, coletaram-se de forma aleatória 200 larvas completas de todas as incubadoras, sendo escolhidas 60 larvas para realizar a análise da progênie. Todas as amostras (nadadeiras e larvas) foram acondicionadas em microtubos de 1,5 ml contendo álcool etílico absoluto para a posterior extração do DNA. A porcentagem de mortalidade dos reprodutores usados no acasalamento definiu-se um dia depois da reprodução.

Para extração de DNA foi utilizado o protocolo de extração com $\mathrm{NaCl}$ descrito por LoperaBarrero et al. (2008). O DNA foi quantificado em espectrofotômetro Shimadzu com absorvância de $260 \mathrm{~nm}$. As amostras foram diluidas para uma concentração de $10 \mathrm{ng} / \mu \mathrm{L}$ (reprodutores) e $5 \mathrm{ng} / \mu \mathrm{L}$ (larvas). Para conferir a qualidade do DNA, foi realizada uma eletroforese em gel de agarose $1 \%$, conduzida em tampão TBE 1X (500mM Tris-HC1, $60 \mathrm{mM}$ ácido bórico e $83 \mathrm{mM}$ EDTA) por uma hora a $70 \mathrm{~V}$. O gel foi visualizado sob radiação UV, depois da sua exposição com brometo de etídio $(0,5 \mu \mathrm{g} /$ $\mathrm{ml}$ ) por uma hora. Posteriormente, a imagem foi fotografada utilizando o programa Kodak EDAS (Kodak 1D Image Analysis 3.5).

O DNA foi amplificado para um volume final de reação de $18 \mu \mathrm{L}$, utilizou-se $1 \mathrm{X}$ do tampão Tris$\mathrm{KCl}, 2,0 \mathrm{mM}$ de $\mathrm{MgCl} 2,0,8 \mu \mathrm{M}$ de cada primer (Forward e Reverse), 0,4 mM de cada dNTP, uma unidade de Platinum Taq DNA Polimerase, 10 ng de DNA para larvas e $20 \mathrm{ng}$ de DNA para os reprodutores. Inicialmente o DNA foi desnaturado a $94^{\circ} \mathrm{C}$ por quatro minutos e em seguida foram realizados 30 ciclos, cada um consistindo de um minuto de desnaturação a $94^{\circ} \mathrm{C}$; um minuto a $54^{\circ} \mathrm{C}, 60^{\circ} \mathrm{C}, 51^{\circ} \mathrm{C}$ e $51^{\circ} \mathrm{C}$ de anelamento para cada locus utilizado e um minuto de extensão a $72^{\circ} \mathrm{C}$. Após, realizou-se uma extensão final a $72^{\circ} \mathrm{C}$ por 10 minutos. Foram amplificados quatro locus descritos por Barroso et al. (2003) para Brycon opalinus (BoM1-AF513621; BoM2-AF513622; BoM5-AF513623 e BoM7-AF513626). As reações foram realizadas em termociclador "Eppendorf Mastercycler ${ }^{\circledR}$ Gradient”.

As amostras amplificadas foram submetidas à eletroforese em gel de poliacrilamida $10 \%$ (acrilamida : bisacrilamida - $29: 1$ ) desnaturante (6 $\mathrm{M}$ de uréia), e conduzida em tampão TBE $1 \mathrm{X}$ (90 mM de Tris-Borato e 2 mM de EDTA) com 320 $\mathrm{V}$ e $250 \mathrm{~mA}$ por sete horas. Para a visualização dos alelos microssatélites, foi utilizada a coloração com nitrato de prata pelo método descrito por Bassan, Caetano-Anollés e Gresshoff (1991) modificado. O gel foi submetido a uma solução de fixação $(10 \%$ de etanol e $0,5 \%$ de ácido acético) por 20 minutos; em seguida corado ( $6 \mathrm{mM}$ de nitrato de prata) por 10 minutos; e posteriormente visualizado $(0,75 \mathrm{M}$ de $\mathrm{NaOH}$ e $0,22 \%$ de formol- $40 \%$ ) e fotografado com câmera Nikon CoolPix 5200.

O tamanho dos alelos foi calculado pelo programa Kodak EDAS-290, utilizando DNA ladder (Invitrogen) de 10, 50 e 100 pb. Esses alelos foram organizados em matrizes de dados que foram submetidas aos programas computacionais que calcularam vários parâmetros que permitiram a determinação da diversidade genética intra e inter populacional. 
O número de alelos, a heterozigosidade observada (Ho) e esperada (He), o índice de Shannon, a distância e identidade genética e o número efetivo de alelos foram calculados utilizado o programa PopGene 1.31 (YEH; BOYLE; XIYAN, 1999). A frequência alélica e a deficiência ou excesso de heterozigotos foram determinados para cada locus por meio do programa GENEPOP 1.2 (RAYMOND; ROUSSET, 1995). O teste do equilíbrio de HardyWeinberg e o desequilíbrio de ligação foram calculados utilizando-se o programa Arlequin 3.1 (EXCOFFIER; LAVAL; SCHNEIDER, 2005) pelo método da cadeia de Markov. A diversidade genética de Nei (1978) e o coeficiente de endogamia (Fis) foram determinados pelo programa FSTAT 2.9.3.2 (GOUDET, 2002). Os valores de contribuição reprodutiva foram obtidos através do programa
PAPA versão 2.0 (DUCHESNE; GODBOUT; BERNATCHEZ, 2002).

\section{Resultados e Discussão}

\section{Sistema por extrusão $x$ Sistema seminatural}

O número de alelos, o tamanho em pares de base e a frequência dos alelos para os diferentes loci microssatélites nos dois sistemas reprodutivos são mostrados na Tabela 1. Os quatro loci utilizados produziram um total de 11 alelos, sendo observados três alelos (BoM1, BoM5 e BoM7) e dois alelos (BoM2) por locus presentes nos parentais e na progênie. Com relação ao tamanho dos alelos, foram observados tamanhos de fragmentos amplificados entre 136 pb (BoM5) e 200 pb (BoM2).

Tabela 1. Número de alelos por locus (Â), tamanho em pares de base (pb) e frequência dos alelos (A, B e C) para os parentais e para a progênie de Brycon orbignyanus, nos sistemas reprodutivos por extrusão e seminatural.

\begin{tabular}{ccccc}
\hline \multicolumn{5}{c}{ Sistema por extrusão } \\
\hline Loci & $\hat{\mathrm{A}}$ & $\mathrm{pb}$ & Parentais & Progênie \\
\hline BoM1 & 3 & $168-144$ & $0,500 / 0,100 / 0,400$ & $0,500 / 0,217 / 0,283$ \\
BoM2 & 2 & $200-170$ & $0,500 / 0,500$ & $0,491 / 0,509$ \\
BoM5 & 3 & $144-136$ & $0,350 / 0,400 / 0,250$ & $0,474 / 0,095 / 0,431$ \\
BoM7 & 3 & $198-188$ & $0,300 / 0,500 / 0,200$ & $0,441 / 0,500 / 0,059$ \\
\hline \multicolumn{7}{c}{} & Sistema seminatural & $0,500 / 0,211 / 0,289$ \\
\hline BoM1 & 3 & $168-144$ & $0,500 / 0,200 / 0,300$ & $0,610 / 0,390$ \\
BoM2 & 2 & $200-170$ & $0,550 / 0,450$ & $0,400 / 0,500 / 0,100$ \\
BoM5 & 3 & $144-136$ & $0,400 / 0,500 / 0,100$ & $0,462 / 0,333 / 0,205$ \\
BoM7 & 3 & $198-188$ & $0,450 / 0,350 / 0,200$ & \\
\hline
\end{tabular}

Fonte: Elaboração dos autores.

De forma geral, foram observados alelos de alta frequência nos parentais e nas progênies dos dois sistemas e não foram encontrados alelos exclusivos. Para o sistema por extrusão, as frequências se apresentaram desiguais entre parentais e progênie em todos os loci. Na progênie os loci BoM1, BoM2, BoM5 e BoM7 apresentaram um aumento na frequência dos alelos B, B, C e A, respectivamente, sendo também observados alelos de baixa frequência (menor que 0,100) para os locus BoM5 (Alelo $\mathrm{B}=0,095$ ) e BoM7 (alelo $\mathrm{C}=0,059$ ). Por outro lado, para a progênie do sistema seminatural, as frequências dos alelos se mantiveram estáveis sendo verificada uma frequência desigual para cada locus. Para os loci BoM1, BoM2 e BoM7 o alelo de maior frequência foi o $\mathrm{A}$, enquanto que para o locus BoM5 o alelo B apresentou maior valor.

Em todos os loci, a riqueza alélica $(\mathrm{Ra})$ foi maior que o número efetivo de alelos (Âe) (Tabela 2), o que confirma a distribuição desigual das frequências alélicas com a presença de alelos de baixa frequência. Essa distribuição de frequências 
e da riqueza alélica pode influenciar a presença de de conservação (INNES; ELLIOTT, 2006, heterozigotos, provocar diminuição da variabilidade CABALLERO; RODRÍGUEZ-RAMILO, 2010). genética e influenciar as decisões num programa

Tabela 2. Riqueza alélica (Ra), número efetivo de alelos (Âe), índice de Shannon (IS) e diversidade genética de Nei (DGN), calculados nos parentais e na progênie de Brycon orbignyanus, nos sistemas reprodutivos por extrusão e seminatural.

\begin{tabular}{|c|c|c|c|c|c|}
\hline Grupo & Locus & $\mathrm{Ra}$ & $\hat{\mathrm{Ae}}$ & IS & DGN \\
\hline \multicolumn{6}{|c|}{ Sistema por extrusão } \\
\hline \multirow[t]{4}{*}{ Parentais } & BoM1 & 3 & 2,381 & 0,937 & 0,604 \\
\hline & BoM2 & 2 & 2,000 & & \\
\hline & BoM5 & 3 & 2,898 & & \\
\hline & BoM7 & 3 & 2,632 & & \\
\hline \multirow[t]{4}{*}{ Progênie } & BoM1 & 3 & 2,651 & 0,886 & 0,566 \\
\hline & BoM2 & 2 & 1,999 & & \\
\hline & BoM5 & 3 & 2,383 & & \\
\hline & BoM7 & 3 & 2,232 & & \\
\hline \multicolumn{6}{|c|}{ Sistema seminatural } \\
\hline \multirow[t]{4}{*}{ Parentais } & BoM1 & 3 & 2,632 & 0,927 & 0,593 \\
\hline & BoM2 & 2 & 1,980 & & \\
\hline & BoM5 & 3 & 2,381 & & \\
\hline & BoM7 & 3 & 1,274 & & \\
\hline \multirow[t]{4}{*}{ Progênie } & BoM1 & 3 & 2,645 & 0,924 & 0,581 \\
\hline & BoM2 & 2 & 1,907 & & \\
\hline & BoM5 & 3 & 2,381 & & \\
\hline & BoM7 & 3 & 2,731 & & \\
\hline
\end{tabular}

Fonte: Elaboração dos autores.

$\mathrm{O}$ baixo número de alelos por locus (dois e três alelos) observado neste estudo pode estar correlacionado à dificuldade na utilização dos loci heterólogos (desenvolvidos para Brycon opalinus), o que faz sugerir a utilização de outros loci na realização de futuros estudos genéticos em B. orbignyanus. Esses resultados concordam com os encontrados por Barroso et al. (2003), onde foram observados poucos alelos para $B$. orbignyanus. Outros estudos têm determinado a dificuldade na utilização de loci heterólogos em estudos com peixes. Lopera Barrero et al. (2010a) e Rodriguez-Rodriguez et al. (2010) ao analisarem a diversidade genética de estoques de Brycon orbignyanus observaram baixo número de alelos (dois e três por locus) indicando a dificuldade na utilização de loci heterólogos. Ao desenvolver microssatélites para Brycon hilarii Sanches e Galetti
Junior (2006) observaram baixo polimorfismo para B. orbignyanus (três alelos). Santos, Hrbek e Farias (2009) trabalhando com loci desenvolvidos para Colossoma macropomum observaram uma baixa amplificação de alelos (dois por locus) em Pygocentrus nattereri, Mylossoma aureum e Piaractus brachypomus. Olivatti et al. (2011) testaram a amplificação de primers heterólogos em Leporinus Friderici encontrando um número baixo de alelos amplificados (um e três alelos).

A presença dos mesmos alelos nos reprodutores e na progênie e a ausência de alelos exclusivos sugere que o estoque de reprodutores apresenta uma adequada variabilidade genética. De forma geral, não ocorreu perda significativa de alelos na formação das progênies nem houve grande quantidade de alelos de baixa frequência. A 
heterozigosidade observada (Ho) nos parentais de ambos os sistemas reprodutivos foi alta para os loci BoM1, BoM5 e BoM7 (1,000), sendo caracterizada uma menor heterozigosidade para o locus BoM2 (0,600 e 0,900 para o sistema por extrusão e seminatural, respectivamente) (Tabela 3 ). Ao serem analisados por sexo encontrou-se igualmente uma alta heterozigosidade observada no sistema por extrusão (fêmeas: $\mathrm{Ho}=0,950 \mathrm{e} \mathrm{He}=0,606$; machos: $\mathrm{Ho}=0,850$ e $\mathrm{He}=0,661$ ) e seminatural (fêmeas: Ho $=0,950$ e $\mathrm{He}=0,644$; machos: $\mathrm{Ho}=1,000$ e $\mathrm{He}=$ $0,645)$.

Tabela 3. Heterozigosidade observada (Ho) e esperada (He), coeficiente de endogamia (Fis) e teste de probabilidade para o equilíbrio de Hardy-Weinberg (PHW) calculados nos parentais e na progênie de Brycon orbignyanus, nos sistemas reprodutivos por extrusão e seminatural.

\begin{tabular}{|c|c|c|c|c|c|}
\hline Parâmetro & BoM1 & BoM2 & BoM5 & BoM7 & Média \\
\hline \multicolumn{6}{|c|}{ Sistema por extrusão } \\
\hline \multicolumn{6}{|c|}{$\underline{\text { Parentais }}$} \\
\hline Но & $1,000^{*}$ & $0,600 \mathrm{~ns}$ & $1,000 *$ & $1,000 *$ & $0,900 *$ \\
\hline $\mathrm{He}$ & 0,610 & 0,526 & 0,689 & 0,652 & 0,619 \\
\hline Fis & $-0,698$ & $-0,149$ & $-0,488$ & $-0,579$ & $-0,478$ \\
\hline PWH & $(0,0003)^{*}$ & $(0,0000)^{*}$ & $(0,0013)^{*}$ & $(0,0005)^{*}$ & - \\
\hline \multicolumn{6}{|c|}{ Progênie } \\
\hline Ho & $1,000^{*}$ & $0,291 *$ & $1,000 *$ & $1,000^{*}$ & $0,823 *$ \\
\hline $\mathrm{He}$ & 0,629 & 0,504 & 0,585 & 0,550 & 0,567 \\
\hline Fis & $-0,600$ & $0,426 * *$ & $-0,719$ & $-0,809$ & $-0,425$ \\
\hline PWH & $(0,0000)^{*}$ & $(0,0001)^{*}$ & $(0,0000)^{*}$ & $(0,0000)^{*}$ & - \\
\hline \multicolumn{6}{|c|}{ Sistema seminatural } \\
\hline \multicolumn{6}{|c|}{$\underline{\text { Parentais }}$} \\
\hline Но & $1,000 *$ & $0,900 *$ & $1,000^{*}$ & $1,000 \mathrm{~ns}$ & $0,975^{*}$ \\
\hline $\mathrm{He}$ & 0,653 & 0,521 & 0,610 & 0,689 & 0,618 \\
\hline Fis & $-0,579$ & $-0,800$ & $-0,698$ & $-0,538$ & $-0,654$ \\
\hline PWH & $(0,0005)^{*}$ & $(0,0007)^{*}$ & $(0,0004)^{*}$ & $(0,0012)^{*}$ & - \\
\hline \multicolumn{6}{|c|}{ Progênie } \\
\hline Ho & $1,000^{*}$ & $0,780 *$ & $1,000 *$ & $1,000 \mathrm{~ns}$ & $0,945^{*}$ \\
\hline $\mathrm{He}$ & 0,627 & 0,480 & 0,585 & 0,642 & 0,583 \\
\hline Fis & $-0,602$ & $-0,634$ & $-0,720$ & $-0,569$ & $-0,631$ \\
\hline PWH & $(0,0000)^{*}$ & $(0,0000)^{*}$ & $(0,0000)^{*}$ & $(0,0000)^{*}$ & - \\
\hline
\end{tabular}

* Significativo $(\mathrm{P}<0.01)$, ** Perda de heterozigotos, (ns) não significativo.

Fonte: Elaboração dos autores.

Esses resultados demonstram que existe uma adequada variabilidade genética intra-populacional, o que faz supor que o plantel de reprodutores se formou a partir de um número grande de reprodutores que permitiu conservar um adequado perfil genético, não sendo influenciado pelo efeito fundador, que é a perda de variação genética quando uma população se forma a partir de um número pequeno de indivíduos provenientes de uma população maior (CAUJAPÉCASTELLS, 2006). Esta afirmação foi corroborada pelos valores de índice de Shannon-IS (0,937 e
0,927 para o sistema por extrusão e seminatural, respectivamente) e de diversidade genética de NeiDGN (0,604 e 0,593 para o sistema por extrusão e seminatural, respectivamente) que ratificaram uma alta variabilidade genética dentro de cada grupo (Tabela 2).

Em outro contexto, através da utilização do sistema reprodutivo seminatural, não houve mortalidade dos reprodutores utilizados (verificado um dia depois do processo reprodutivo) e ocorreu 
a preservação da variabilidade genética na progênie, demonstrando a efetividade desse sistema reprodutivo. Por outro lado, apesar de obter-se uma desova total dos gametas, no sistema por extrusão somente um reprodutor (macho) sobreviveu a este manejo reprodutivo (verificado um dia depois do procedimento). Povh (2007) comparando o sistema de reprodução seminatural e por extrusão em um cruzamento de 20 reprodutores $(10 \AA \mathrm{e}$ 10) de Piaractus mesopotamicus encontrou uma maior variabilidade genética na progênie do sistema seminatural (IS $=0,415$ e $\%$ Fragmentos polimórficos- $\% \mathrm{FP}=72,4 \%$ ) quando comparada com o sistema por extrusão (IS $=0,231$ e $\% \mathrm{FP}=$ $42,7 \%$ ) e uma mortalidade maior no sistema por extrusão. Reynalte-Tataje et al. (2002) investigando a reprodução de Leporinus macrocephalus, não encontraram mortalidade dos reprodutores ao utilizar o sistema seminatural, diferentemente do sistema por extrusão onde esses resultados chegaram a $66,7 \%$.

\section{Sistema reprodutivo por extrusão}

Ao comparar os parentais e a progênie do sistema reprodutivo por extrusão observou-se desvio dos valores de heterozigosidade esperada $(\mathrm{He})$ nos reprodutores e na progênie, o que caracteriza os desvios significativos no equilíbrio de HardyWeinberg (Tabela 3). Segundo Romana-Eguia et al. (2004) e Wasko et al. (2004) isto é sempre esperado em estoques mantidos em cativeiro, já que os desvios nas frequências provocadas eventualmente pela deriva genética tendem a ampliar-se com o passo das gerações, reduzindo a variabilidade genética.

O desequilíbrio de ligação, que é a associação não aleatória de alelos em dois ou mais loci (CAUJAPÉCASTELLS, 2006) foi observado em quatro diferentes pares (BoM1xBoM2, BoM1xBoM5, BoM1xBoM7 e BoM5xBoM7). Verificou-se que apesar da alta variabilidade genética intrapopulacional (IS $=0,886$ e DGN $=0,566$ ) houve uma diminuição da variabilidade genética na progênie, a qual também foi evidenciada pelos valores de heterozigosidade média observada $(0,900$ e 0,823 para parentais e progênie, respectivamente). A redução da heterozigosidade, de acordo com Ramos et al. (2012) pode ocasionar a perda da capacidade de uma população se adaptar a mudanças nas condições ambientais. No caso de alevinos utilizados em programas de repovoamento este evento seria muito prejudicial e conflitaria com a conservação das populações naturais, especialmente aquelas em risco de extinção.

A diminuição da variabilidade genética na progênie pode ter acontecido devido à presença de endogamia na progênie (locus BoM2 Fis = 0,426), viabilizada pela erosão genética, que pode causar deriva genética nas populações naturais. De acordo com Allendorf e Luikard (2007) quanto menor o tamanho efetivo populacional, maior será o efeito da deriva genética sobre uma população. Por outro lado, a utilização de um pool de sêmen pode ter contribuído também com a diminuição da variabilidade genética. Ribolli e ZaniboniFilho (2009) em estudos realizados com Rhamdia quelen, encontraram que o pool de sêmen reduziu a variabilidade genética através do favorecimento da dominância de alguns machos sobre outros na fertilização dos ovócitos. Esses resultados concordam com os encontrados no presente estudo.

Através da análise estatística, foi calculada unicamente $88,4 \%$ da paternidade total na progênie $(\mathrm{P}<0,05)$. Através desse resultado, foi observada uma escassa contribuição reprodutiva de dois parentais (macho 3 - M3 e fêmea 4 - F4), existindo dominância principalmente dos M2, M4 e F2 (Figura 1). Todos os machos contribuíram com a progênie e fertilizaram mais de uma fêmea, caracterizando a paternidade múltipla. Os machos M2, M4 e M5 foram os que fertilizaram um maior número de fêmeas (quatro cada). O M1 e M3 fertilizaram três fêmeas cada. A composição das famílias foi influenciada diretamente pela maior participação do M2 e M4, sendo que os cruzamentos F2xM2 e F5xM4 tiveram a maior contribuição na progênie $(23,3 \%)$. A composição das famílias na progênie de B. orbignyanus é mostrada na Figura 2. 
Figura 1. Contribuição parental da progênie de B. orbignyanus, utilizando o sistema reprodutivo por extrusão.

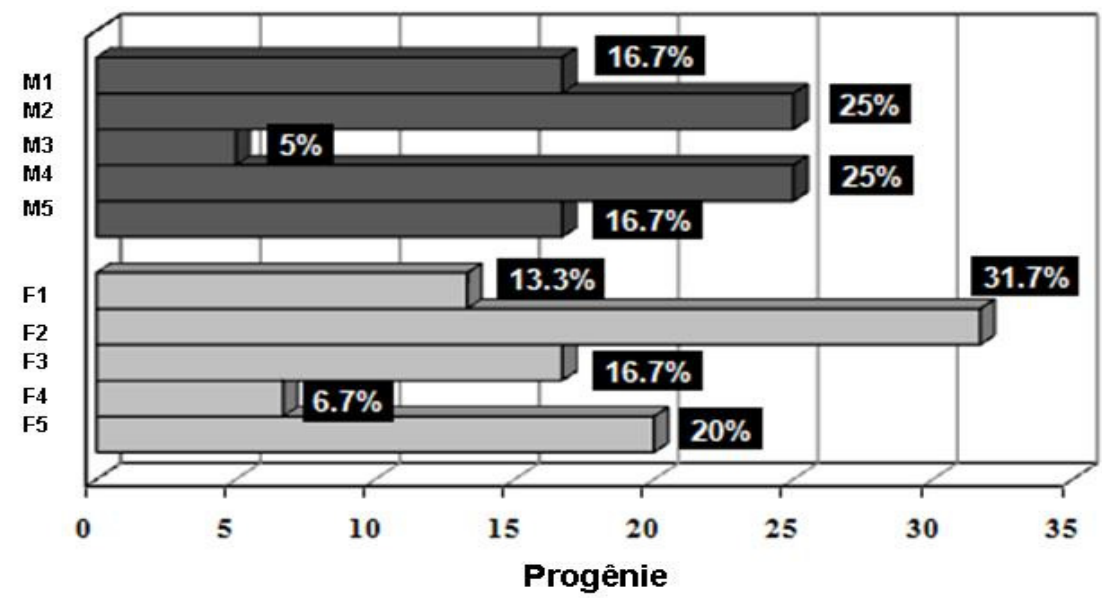

$\square$ MACHOS $\square$ FÊMEAS

Fonte: Elaboração dos autores.

Figura 2. Composição das famílias na progênie de B. orbignyanus, utilizando o sistema reprodutivo por extrusão.

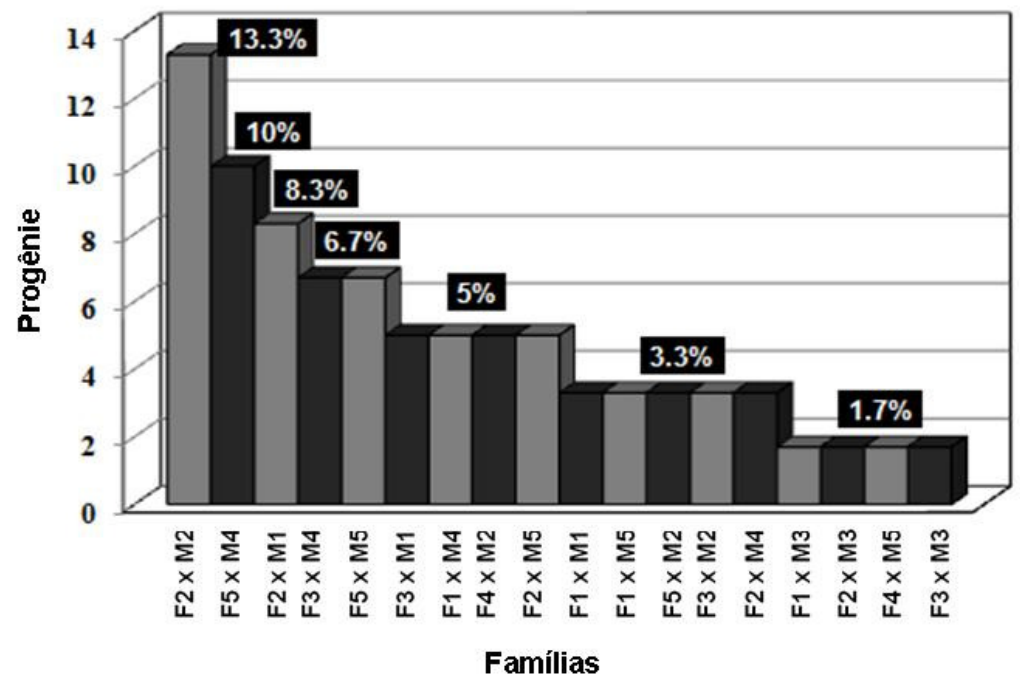

Fonte: Elaboração dos autores.

\section{Sistema reprodutivo seminatural}

Ao comparar os parentais e a progênie do sistema reprodutivo seminatural observou-se desvio dos valores de heterozigosidade esperada (He) nos reprodutores e na progênie, o que igualmente caracterizou os desvios significativos no equilíbrio de Hardy-Weinberg (Tabela 3). Observou-se desequilíbrio de ligação em seis diferentes pares (BoM1xBoM2, BoM1xBoM5, BoM1xBoM7, BoM2xBoM5, BoM2xBoM7 e BoM5xBoM7). $\mathrm{O}$ coeficiente de endogamia (Fis) apresentou valores negativos em todos os loci, indicando a ausência de endogamia na progênie. Verificouse que a variabilidade genética na progênie foi preservada, sendo corroborado pelos valores de 
heterozigosidade média observada $(0,975$ e 0,945 para parentais e progênie, respectivamente), pelos valores de IS $(0,927$ e 0,924 para parentais e progênie, respectivamente) e pela DGN (0,593 e 0,581 para parentais e progênie, respectivamente).

O sistema reprodutivo seminatural pode ter influenciado na preservação da variabilidade genética da progênie, já que esse sistema reduz a seleção não intencional no processo reprodutivo que ocorre normalmente no sistema reprodutivo por extrusão (POVH, 2007) e diminui significativamente a mortalidade causada pelo estresse. Isto permite que um maior número de reprodutores se reproduza durante os cruzamentos e que exista sincronização natural na liberação dos gametas, permitindo que o pool genético de um estoque pequeno ou de um cruzamento com poucos indivíduos (como é normalmente utilizado em programas de repovoamento) seja representado com maior heterogeneidade na progênie (CACHO; YAMAMOTO; CHELLAPPA, 2007, REYNALTETATAJE et al., 2002), devido ao menor efeito seletivo do sistema e à maior taxa de sobrevivência dos reprodutores, o que pode viabilizar a preservação da variabilidade genética na progênie.

Através da análise estatística, foi calculada unicamente $93,4 \%$ da paternidade total na progênie $(\mathrm{P}<0,05)$. Foi observada participação equilibrada da maioria dos parentais na progênie, confirmando as vantagens na utilização de esse sistema em cruzamentos de B. orbignyanus. Entretanto, foi verificada uma maior participação na progênie do M3, caracterizando um efeito de dominância reprodutiva (Figura 3).

Figura 3. Contribuição parental da progênie de B. orbignyanus, utilizando o sistema reprodutivo seminatural.
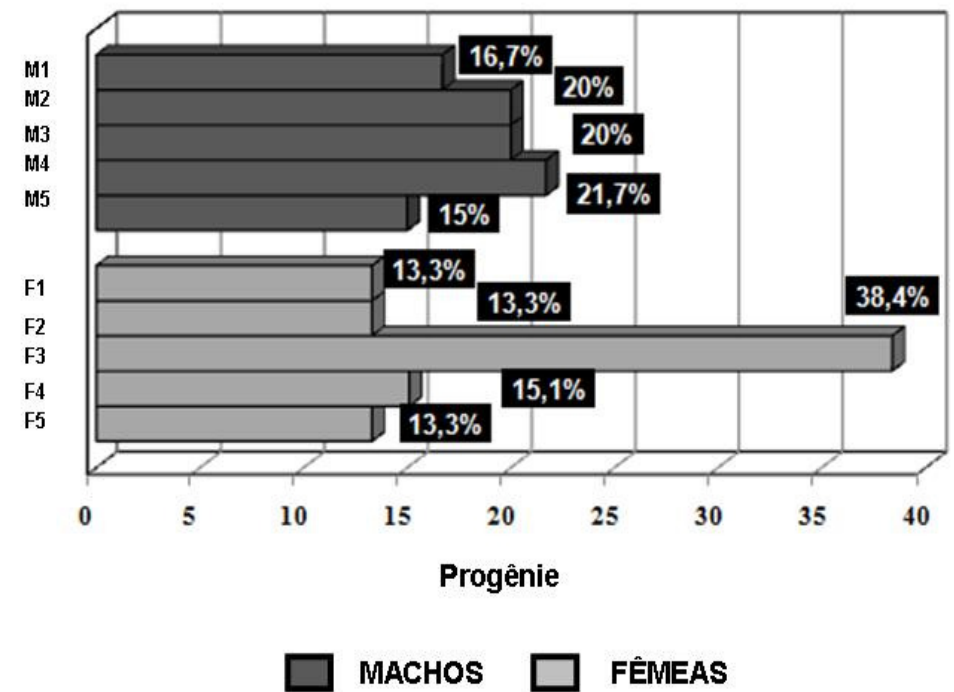

Fonte: Elaboração dos autores.

Pela redução do direcionamento e da seleção não intencional no processo reprodutivo, o sistema seminatural usado no presente estudo permitiu a dominância de reprodutores durante o cruzamento. A dominância reprodutiva, também conhecida como hipótese da qualidade intrínseca do macho ou hipótese do bom esperma (SIVINSKI, 1984), pode influenciar na variabilidade genética quando se usam sistemas reprodutivos seminaturais, já que a dominância de alguns machos na fertilização dos óvulos pode influenciar a variabilidade genética da progênie. De acordo com Alonso et al. (2012) em 
indivíduos Cichlasoma dimerus a dominância está correlacionada nos machos com o tamanho corporal e nas fêmeas com características intrínsecas, tais como a agressividade. Este fenômeno, observado em peixes exóticos (PAULL et al., 2010, PORTA et al., 2006, SPENCE; SMITH, 2006) e nativos brasileiros como o Piaractus mesopotamicus (POVH et al., 2010) e B. orbignyanus (LOPERABARRERO et al., 2010b), foi novamente observado no presente estudo para esta ultima espécie.
Todos os machos contribuíram com a progênie e fertilizaram mais de uma fêmea, caracterizando a paternidade múltipla. O M2 foi quem fertilizou maior quantidade de fêmeas (quatro), seguido do M1, M3 e M4 (três cada) e pelo M5 (dois). A composição das famílias foi influenciada diretamente pela maior participação do M3, sendo que os cruzamentos F3xM3 e F2xM3 tiveram a maior contribuição na progênie $(31,7 \%)$. A composição das famílias na progênie de $B$. orbignyanus é mostrada na Figura 4.

Figura 4. Composição das famílias na progênie de B. orbignyanus, utilizando o sistema reprodutivo seminatural.

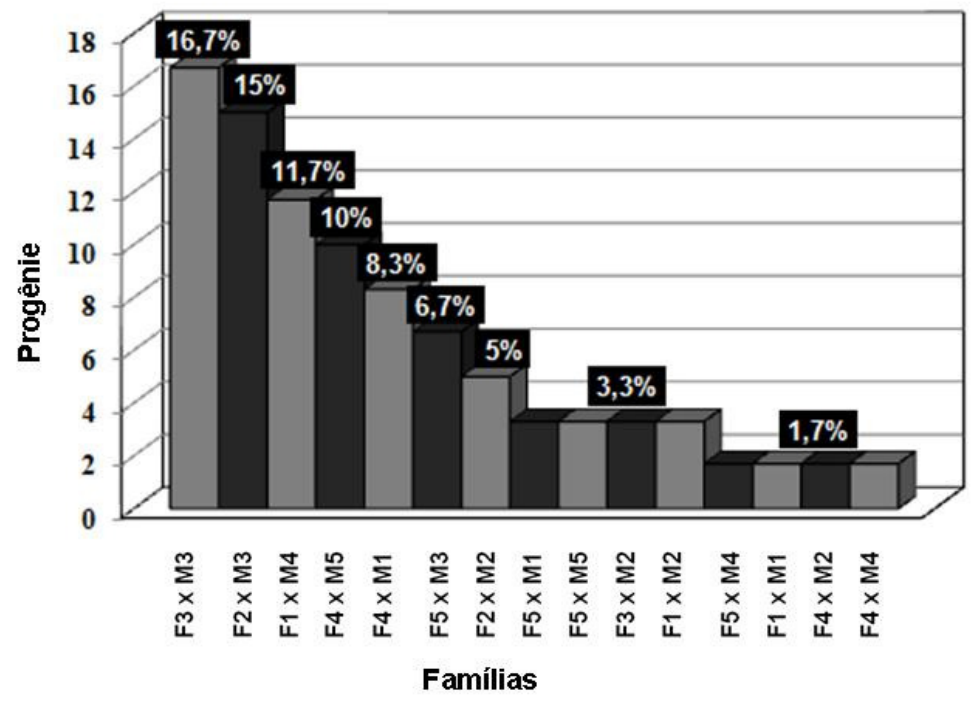

Fonte: Elaboração dos autores.

A partir dos resultados de variabilidade genética, paternidade e conservação física dos reprodutores utilizados nos acasalamentos, pode-se sugerir que o sistema reprodutivo seminatural é indicado para a reprodução do Brycon orbignyanus em ambientes controlados e em programas de repovoamento, já que diminui a mortalidade dos reprodutores durante o processo reprodutivo e permitem a preservação da variabilidade genética.

A diminuição da variabilidade genética pode afetar um programa de repovoamento a partir da baixa sobrevivência de alevinos no ambiente natural e através impactos negativos nas populações de peixes e no ecossistema (GARDNER et al., 2010, SØNSTEBØ; BORGSTRØM; HEUN, 2007; POVH et al., 2008). Assim, através dos resultados observados, o manejo reprodutivo de estoques de $B$. orbignyanus utilizados em programas de repovoamento pode ser orientado corretamente e pode ser utilizado em outras espécies de peixes em risco de extinção. 


\section{Agradecimentos}

Os autores agradecem à Duke Energy International por fornecer os materiais para realizar o presente estudo; e aos estudantes e técnicos que contribuíram com a pesquisa.

\section{Referências}

ALLENDORF, F. W.; LUIKART, G. Conservation and the genetics of populations. Malden: John Wiley and Sons, 2007. $642 \mathrm{p}$.

ALONSO, F.; HONJI, R. M.; MOREIRA, R. G.; PANDOLFI, M. Dominance hierarchies and social status ascent opportunity: Anticipatory behavioral and physiological adjustments in a Neotropical cichlid fish. Physiology \& Behavior, New York, v. 106, n. 5, p. 612618, 2012.

BARROSO, R. M.; HILSDORF, A. W. S.; MOREIRA, H. L. M.; MELLO, A. M.; GUIMARÃES, S. E. F.; CABELLO, P. H.; TRAUB-Cseko, Y. M. Identification and characterization of microsatellites loci in Brycon opalinus (Cuvier, 1819) (Characiforme, Characidae, Bryconiae). Molecular Ecology Notes, Oxford, v. 3, n. 1, p. 297-298, 2003.

BASSAN, B. J.; CAETANO-ANOLLÉS, G.; GRESSHOFF, P. M. Fast and sensitive silver staining of DNA in polyacrylamide gels. Analytical Biochemistry, Bethesda, v. 196, n. 2, p. 80-83, 1991.

BORBA, M. R.; FRACALOSSI, D. M.; PEZZATO, L. E. Dietary energy requirement of piracanjuba fingerlings, Brycon orbignyanus, and relative utilization of dietary carbohydrate and lipid. Aquaculture Nutrition, Malden, v. 12, n. 3, p. 183-191, 2006.

CABALLERO, A.; RODRÍGUEZ-RAMILO, S. T. Management of genetic diversity of subdivided populations in conservation programmes. Conservation Genetics, Dordrecht, v. 11, n. 2, p. 409-419, 2010.

CACHO, M.S.R.F.;YAMAMOTO, M.E.; CHELLAPPA, S. Mating system of the amazonian cichlid angel fish, Pterophyllum scalare. Brazilian Journal of Biology, São Carlos, v. 67, n. 1, p. 161-165, 2007.

CAUJAPÉ-CASTELLS, J. Brújula para botánicos desorientados en la genética de poblaciones. Las Palmas de Gran Canária: Exegen Ediciones, 2006. 133 p.

CECCARELLI, P. S.; SENHORINI, J. A.; RÊGO, R. F. do. Piracanjuba, Brycon orbignyanus (Valenciennes,
1849). In: BALDISSEROTTO, B.; GOMES, L. de C. (Ed.). Espécies nativas para piscicultura no Brasil. Santa Maria: Editora da UFSM, 2005. p. 121.

DUCHESNE, P.; GODBOUT, M. H.; BERNATCHEZ, L. PAPA (Package for the analysis of parental allocation): a computer program for simulated and real parental allocation. Molecular Ecology Notes, Oxford, v. 2, n. 2, p. 191-193, 2002.

EXCOFFIER, L.; LAVAL, G.; SCHNEIDER, S. Arlequin Ver. 3.1: an integrated software package for population genetics data analysis. Evolutionary Bioinformatics Online, Auckland, v. 1, n. 1, p. 47-50, 2005.

GARDNER, M. J.; COTTINGHAM, A.; PHILLIPS, N. M.; HESP, S. A.; CHAPLIN, J. A.; JENKINS, G. I. Biological performance and genetics of restocked and wild Black Bream in the Blackwood river estuary. Western: Report to the West Australian Fish Foundation, $2010.60 \mathrm{p}$.

GOUDET, J. FSTAT: a program to estimate and test gene diversities and fixation indices (version 2.9.3.2), 2002. Disponível em: <http://www2.unil.ch/popgen/softwares/ fstat.htm>. Acesso em: 21 nov. 2012.

IBAMA. Lista de espécies aquáticas ameaçadas de extinção. 2012. Disponível em: <http://www.ibama.gov. $\mathrm{br} /$ institucional/lista-de-especies-aquaticas-ameacadasde-extincao>. Acesso em: 04 dez. 2012.

INNES, B. H.; ELLIOTT, N. G. Genetic diversity in a Tasmanian hatchery population of Atlantic salmon (Salmo salar L.) compared with its Canadian progenitor population. Aquaculture Research, Oxford, v. 37, n. 6, p. 563-569, 2006.

KALINOWSKI, S. T.; DOORNIK, D. M. V.; KOZFKAY, C. C.; WAPLES, R. S. Genetic diversity in the Snake River sockeye salmon captive broodstock program as estimated from broodstock records. Conservation Genetics, Dordrecht, v. 13, n. 5, p. 1183-1193, 2012.

LOPERA-BARRERO, N. M. Conservation of Brycon orbignyanus natural populations and stocks for their reproductive, genetic, environmental sustainability: A model for species threatened with extinction. Ciencia e Investigación Agrária, Santiago, v. 36, n. 2, p. 191-208, 2009.

LOPERA-BARRERO, N. M.; POVH, J. A.; RIBEIRO, R. P.; GOMES, P. C.; JACOMETO, C. B.; LOPES, T. S. Comparison of DNA extraction protocols of fish fin and larvae samples: modified salt $(\mathrm{NaCl})$ extraction. Ciencia e Investigación Agrária, Santiago, v. 35, n. 1, p. 65-74, 2008. 
LOPERA-BARRERO, N. M.; RIBEIRO, R. P.; POVH, J. A. O repovoamento de peixes: uma estratégia multidisciplinar? Aquicultura \& Pesca, São Paulo, v. 30, n. 1, p. 71-74, 2007.

LOPERA-BARRERO, N. M.; RODRIGUEZRODRIGUEZ, M. DEL P.; RIBEIRO, R. P.; POVH, J. A.; VARGAS, L.; STREIT JUNIOR, D. P.; FORNARI, D. C. Reproductive contribution of a Brycon orbignyanus (Cuvier and Valenciennes, 1850) offspring in the seminatural reproductive system using microsatellite markers. Zootecnia Tropical, Maracay, v. 28, n. 3, p. 403-411, 2010b.

LOPERA-BARRERO, N. M.; VARGAS, L.; SIROL, R. N.; RIBEIRO, R. P.; POVH, J. A.; STREIT JUNIOR, D. P.; GOMES, P. C. Genetic diversity and reproductive contribution of Brycon orbignyanus offspring in the semi-natural reproductive system, using microsatellites markers. Agrociencia, Montecillo, v. 44, n. 2, p. 171-181, 2010a.

MELO, D. C.; OLIVEIRA, D. A. A.; RIBEIRO, L. P.; TEIXEIRA, C. S.; SOUZA, A. B.; COELHO, E. G. A.; CREPALDI, D. V.; TEIXEIRA, E. A. Caracterização genética de seis plantéis comerciais de tilápia (Oreochromis) utilizando marcadores microssatélites. Arquivo Brasileiro de Medicina Veterinária e Zootecnia, Belo Horizonte, v. 58, n. 1, p. 87-93, 2006.

NEI, M. Estimation of average heterozygosity and genetic distance from a small number of individual. Genetics, Bethesda, v. 89, n. 3, p. 583-590, 1978.

OLIVATTI, A. M.; BONI, T. A.; SILVA-JÚNIOR, N. J.; RESENDE, L. V.; GOUVEIA, F. O.; TELLES, M. P. C. Heterologous amplification and characterization of microsatellite markers in the Neotropical fish Leporinus friderici. Genetics and Molecular Research, Ribeirão Preto, v. 10, n. 3, p. 1403-1408, 2011.

PANARARI-ANTUNES, R. S.; PRIOLI, A. J.; PRIOLI, S. M. A. P.; GALDINO, A. S.; JULIO JUNIOR, H. F.; PRIOLI, L. M. Genetic variability of Brycon orbignyanus (Valenciennes, 1850) (Characiformes: Characidae) in cultivated and natural populations of the upper Paraná River, and implications for the conservation of the species. Brazilian Archives of Biology and Technology, Curitiba, v. 54, n. 4, p. 839-848, 2011.

PAULL, G. C.; FILBY, A. L.; GIDDINS, H. G.; COE, T. S.; HAMILTON, P. B.; TYLER, C. R. Dominance hierarchies in zebrafish (Danio rerio) and their relationship with reproductive success. Zebrafish, Larchmont, v. 7, n. 1, p. 109-117, 2010.

PEREZ-ENRIQUEZ, R.; HERNÁNDEZ-MARTÍNEZ, F.; CRUZ, P. Genetic diversity status of white shrimp
Penaeus (Litopenaeus) vannamei broodstock in Mexico. Aquaculture, Amsterdam, v. 297, n. 1-2, p. 44-50, 2009.

PORTA, J.; PORTA, J. M.; MATÍNEZ-RODRÍGUEZ, G.; ALVAREZ, M. C. Genetic structure and genetic relatedness of a hatchery stock of Senegal sole (Solea senegalensis) inferred by microsatellites. Aquaculture, Amsterdam, v. 251, n. 1, p. 46-55, 2006.

POVH, J. A. Avaliação da diversidade genética e do manejo reprodutivo do pacu, Piaractus mesopotamicus. 2007. Tese (Doutorado em Zootecnia) - Programa de Pós-Graduação em Zootecnia. Universidade Estadual de Maringá, Maringá.

POVH, J. A.; RIBEIRO, R. P.; LOPERA-BARRERO, N. M.; JACOMETO, C. B.; VARGAS, L.; GOMES, P. C.; LOPES, T. S. Microsatellite analysis of pacu broodstocks used in the stocking program of Paranapanema River, Brazil. Scientia Agrícola, Piracibaba, v. 68, n. 3, p. 308313, 2011.

POVH, J. A.; RIBEIRO, R. P.; SIROL, R. N.; STREIT JR, D. P.; MOREIRA, H. L. M.; SIEWERDT, F.; LOPERABARRERO, N. M.; MANGOLIN, C. A.; VARGAS, L. Microsatellite Analysis of the Parental Contribution of Piaractus mesopotamicus to the Production of Offspring in the Semi-natural System of Reproduction. Brazilian Archives of Biology and Technology, Curitiba, v. 53, n. 2, p. 389-396, 2010.

POVH, J. A.; RIBEIRO, R. P.; SIROL, R. N.; STREIT JÚNIOR, D. P.; LOPERA-BARRERO, N. M.; VARGAS, L.; GOMES, P. C.; LOPES, T. S. Genetic diversity of pacu from the Paranapanema River and from the broodstock of a stock enhancement program. Pesquisa Agropecuaria Brasileira, Brasília, v. 43, n. 2, p. 201-206, 2008.

RAMOS, J. V. B.; SODRÉ, L. M. K.; ORSI, M. L.; ALMEIDA, F. S. Genetic diversity of the species Leporinus elongatus (Teleostei: Characiformes) in the Canoas Complex - Paranapanema River. Neotropical Ichthyology, São Paulo, v. 10, n. 4, p. 821-828, 2012.

RAYMOND, M.; ROUSSET, F. An exact test for population differentiation. Evolution, Malden, v. 49, n. 6, p. 1280-1283, 1995.

REYNALTE-TATAJE, D. A.; LUZ, R. K.; MEURER, S.; ZANIBONI-FILHO, E.; NUÑER, A. P. de O. Influência do fotoperíodo no crescimento e sobrevivência de póslarvas de piracanjuba Brycon orbignyanus (Valenciennes, 1849) (Osteichthyes, Characidae). Acta Scientiarum Animal Sciences, Maringá, v. 24, n. 2, p. 439-443, 2002.

RIBOLLI, J.; ZANIBONI-FILHO, E. Individual contributions to pooled-milt fertilizations of silver catfish Rhamdia quelen. Neotropical Ichthyology, São Paulo, v. 7, n. 4, p. 629-634, 2009. 
RICHARDS, C. L.; WARES, J. P.; MACKIE, J. A. Evaluating adaptive processes for conservation and management of estuarine and coastal resources. Estuaries and Coasts, Port Republic, v. 33, n. 4, p. 805-810, 2010.

RODRIGUEZ-RODRIGUEZ, M. DEL P.; LOPERABARRERO, N. M.; RIBEIRO, R. P.; POVH, J. A.; VARGAS, L.; SIROL, R. N.; JACOMETO, C. B. Genetic diversity of piracanjuba used in stock enhancement programs with microsatellite markers. Pesquisa Agropecuária Brasileira, Brasília, v. 45, n. 1, p. 56-63, 2010.

ROMANA-EGUIA, M. R. R.; IKEDA, M.; BASIAO, Z. U.; TANIGUCHI, N. Genetic diversity in farmed Asian Nile and red hybrid tilapia stocks evaluated from microsatellite and mitochondrial DNA analysis. Aquaculture, Amsterdam, v. 236, n. 1-4, p. 131-150, 2004.

SANCHES, A.; GALETTI JUNIOR, P. M. Microsatellites loci isolated in the freshwater fish Brycon hilarii. Molecular Ecology Notes, Oxford, v. 6, n. 4, p. 10451046, 2006.

SANTOS, M da C. F.; HRBEK, T.; FARIAS, I. P. Microsatellite markers for the tambaqui (Colossoma macropoтит, Serrasalmidae, Characiformes), na economically important keystone species of the Amazon River floodplain. Molecular Ecology Resources, Oxford, v. 9, n. 3, p. 874-876, 2009.

SIVINSKI, J. Sperm in competition. In: SMITH, R. L. (Ed.). Sperm competition and the evolution of animal mating systems. London: Academic Press, 1984. p. 86115.
SØNSTEBØ, J. H.; BORGSTRØM, R.; HEUN, M. Genetic structure of brown trout (Salmo trutta L.) from the Hardangervidda mountain plateau (Norway) analyzed by microsatellite DNA: a basis for conservation guidelines. Conservation Genetics, Dordrecht, v. 8, n. 1, p. 33-44, 2007.

SPENCE, R.; SMITH, C. Mating preference of female zebrafish, Danio rerio, in relation to male dominance. Behavioral Ecology, New York, v. 17, n. 5, p. 779-783, 2006.

WASKO, A. P.; MARTINS, C.; OLIVEIRA, C.; SENHORINI, J. A.; FORESTI, F. Genetic monitoring of the Amazonian fish matrinchã (Brycon cephalus) using RAPD markers: insights into supportive breeding and conservation programmers. Journal of Applied Ichthyology, Hamburg, v. 20, n. 1, p. 48-52, 2004.

YEH, F. C.; BOYLE, T. Y. Z.; XIYAN, J. M. POPGENE version 131: microsoft window-based freeware for population genetic analysis. Alberta: University of Alberta and Center for International Forestry Research, 1999. $29 \mathrm{p}$.

ZANIBONI-FILHO, E.; NUÑER, A. P. O. Reprodução de peixes migradores de água doce. In: CYRINO, J. E. P.; URBINATI, E. C.; FRACALOSSI, D. M.; CASTAGNOLLI, N. (Ed.). Tópicos especiais em piscicultura de água doce tropical intensiva. São Paulo: TecArt, 2004. p. 63-64.

ZANIBONI-FILHO, E.; REYNALTE-TATAJE, D.; WEINGARTNER, M. Potencialidad del género Brycon en la piscicultura brasileña. Revista Colombiana de Ciências Pecuárias, Medellín, v. 19, n. 2, p. 233-240, 2006. 